\title{
Knowledge of vaccination of allergic children among Italian primary care pediatricians, hospital pediatricians and pediatric residents
}

\author{
Susanna Esposito ${ }^{\mathrm{a}, *}$, Chiara Azzari $^{\mathrm{b}}$, Giorgio Bartolozzi $^{\mathrm{b}}$, Gaetano Maria Fara $^{\mathrm{c}}$, \\ Franco Giovanetti ${ }^{\mathrm{d}}$, Milena Lo Giudice ${ }^{\mathrm{e}}$, Carlotta Galeone ${ }^{\mathrm{f}}$, \\ Marta Ciofi degli Atti ${ }^{\mathrm{g}}$, for the Italian Society of Pediatric Allergy and Immunology \\ a Department of Maternal and Pediatric Sciences, Università degli Studi di Milano, Fondazione IRCCS Ca' Granda Ospedale Maggiore Policlinico, \\ Via Commenda 9, 20122 Milano, Italy \\ ${ }^{\mathrm{b}}$ Department of Pediatrics, University of Florence, Florence, Italy \\ ${ }^{\mathrm{c}}$ Department of Public Health, Università La Sapienza, Rome, Italy \\ d Department of Prevention, ASL CN2, Alba, Bra, Italy \\ e Primary Care Pediatrician, Palermo, Italy \\ ${ }^{\mathrm{f}}$ Department of Epidemiology, Istituto di Ricerche Farmacologiche Mario Negri, Milan, Italy \\ ${ }^{g}$ Direzione Sanitaria, IRCCS Bambino Gesù Hospital, Rome, Italy
}

\section{A R T I C L E I N F O}

\section{Article history:}

Received 6 June 2010

Received in revised form 5 July 2010

Accepted 7 July 2010

\section{Keywords:}

Allergic patients

Allergy

Children

Prevention

Safety

Vaccination

\begin{abstract}
A B S T R A C T
A cross-sectional survey of Italian pediatricians and pediatric residents was carried out between 15 September and 18 October 2008 in order to evaluate their knowledge concerning the administration of vaccines to children with suspected or proved allergies. Of the 750 physicians who accepted to participate ( 620 pediatricians and 130 residents), 630 (84.0\%; 407 females; mean age $43.5 \pm 11.2$ years) returned completed questionnaires: 268 primary care pediatricians (42.5\%), 244 hospital pediatricians (38.8\%), and 118 pediatric residents (18.7\%). Knowledge concerning the vaccination of children with suspected or proved allergies was far from optimal, with the poorest knowledge being shown by the pediatric residents and no difference between the primary care and hospital pediatricians. Since pediatricians are the main parents' advisors regarding vaccinations, these results indicate an urgent need for educational programmes (especially for residents) and evidence-based guidelines concerning vaccinations in children with suspected or proved allergies.
\end{abstract}

(c) 2010 Elsevier Ltd. All rights reserved.

\section{Introduction}

The administration of vaccines to infants and children has had an extraordinarily beneficial impact on public health by reducing morbidity, mortality and the social and economic burden associated with a number of common infectious diseases [1]. However, despite these benefits, the use of vaccines is frequently debated and opposed by a substantial number of parents and misguided experts because they think that negative aspects (mainly adverse events) significantly outweigh the advantages [2]. Furthermore, putative vaccine safety issues are frequently reported in the media and scientific literature, whereas there are few reviews of the benefits [1].

The primary care pediatricians who usually take care of children have the greatest influence over parental decisions regarding the acceptance or refusal of vaccines $[3,4]$. Benin et al. found that trust

\footnotetext{
* Corresponding author. Tel.: +39 02 55032203, fax: +39 0250320206.

E-mail address: Susanna.esposito@unimi.it (S. Esposito).
}

or a lack of trust, and relationships with a pediatrician or another influential person, are pivotal in the decision-making of new mothers [3]. However, communicating the risks and benefits of vaccines does not always meet parents' needs because a number of pediatricians do not accept patients whose parents refuse vaccination, and pediatricians' knowledge of infant vaccination recommendations is generally quite poor [5]. Various studies have clearly demonstrated that, particularly when new vaccines are included in the immunization schedules recommended by health authorities, pediatricians do not always know the schedules themselves or the related contraindications and this may contribute towards increasing the number of missed opportunities to immunize [6-11].

The parents who oppose vaccines or refuse vaccinations frequently do so because they fear adverse events, including allergic reactions, although post-vaccination allergic reactions are very rare [12-16]: an analysis of spontaneously reported suspected adverse drug reactions after the administration of 15 marketed vaccines from 1994 to 1998 found that only one case was reported per 450,000 sold vaccine doses [12]. The risk of anaphylaxis and potentially life-threatening events after the vaccination of children and 
adolescents is also extremely low [12-16], and there is no evidence of an increased risk of adverse reactions in patients who are allergic to substances not included in vaccines $[13,17,18]$. The adequate knowledge of the pediatrician concerning true and false contraindications to vaccines has a major role in the advice given to parents of allergic children $[5,6]$.

No data are available concerning pediatrician's knowledge of vaccines' recommendations for allergic patients, or the information the pediatricians can give to parents who fear adverse events when vaccines are given to their atopic children. As such data may be important in defining educational programmes capable of increasing vaccination coverage, the aim of this study was to assess knowledge of vaccines' recommendations for children with suspected or proved allergy with different clinical presentations and variously severe diseases among different categories of Italian pediatricians. Special emphasis was placed on the use of measles, mumps and rubella (MMR) and influenza vaccinations in children with egg allergy because of the extensive published literature and changes in current knowledge [19-25].

\section{Patients and methods}

\subsection{Study design}

A cross-sectional survey of Italian pediatricians and pediatric residents was carried out between 15 September and 18 October 2008 in order to evaluate their attitudes and behaviour concerning the administration of vaccines to allergic children. The sample included representatives from the two different categories of pediatricians operating in Italy (primary care pediatricians who only take care of children in the community, and exclusively hospital pediatricians) and a representative group of post-graduate physicians studying to become specialist pediatricians.

The study was approved by the Ethics Committee of the University of Milan, Italy, and informed consent was obtained from all of the participants before study entry.

\subsection{Study population}

All of the pediatricians and pediatric residents duly registered at the Annual Congress of the Italian Society of Pediatrics held in Genoa, Italy, on 15-18 October 2008 were considered theoretically eligible for enrolment; this Congress is usually attended by about $20-25 \%$ of all Italian pediatricians and a similar proportion of pediatric residents. They were all sent an e-mail 30 days before the beginning of the meeting in which they were asked whether they would be willing to respond to a brief questionnaire regarding vaccines and vaccination practices during the Congress.

Applying the relative prevalence of pediatricians and pediatric residents to a targeted sample size of 800 , we calculated the expected number of responders assuming a response rate of $75-80 \%$, and ascertained that 600 completed questionnaires would yield a power of $80 \%$ with a $5 \%$ type 1 error rate to detect a $16 \%$ difference when comparing dichotomous variables between two groups of equal size.

In order to compare characteristics of the pediatricians attending to the Annual Congress with those of all Italian pediatricians and to evaluate representativeness of the sample who participated to the survey, we collected demographic characteristics of pediatricians who returned the questionnaire.

\subsection{Questionnaire and its administration}

A self-administered anonymous questionnaire was distributed during the Congress at registration desk to all the participants who accepted to participate in the survey (83\% of the Conference attendees), together with a stamped envelope addressed to the trained study researchers (SE, MC). The questionnaire, which had been prepared by a multidisciplinary group of pediatricians (SE, CA, GB, MLG), epidemiologists (CG, MC), and public health physicians (FG, $\mathrm{GF}$ ), was pilot-tested on a convenience sample of primary care pediatricians, hospital pediatricians and pediatric residents in order to ensure clarity and ease of administration. It included three sections assessing: (1) the general characteristics of the enrolled physicians; (2) their knowledge of the conditions requiring special precautions in the administration of vaccines; (3) and their knowledge of the use of vaccines in children with documented allergic diseases.

\subsection{Statistical analysis}

Continuous variables are given as mean values \pm standard deviation (SD), and categorical variables as numbers and percentages. The continuous data were analysed using a two-sided Student's test if they were normally distributed (on the basis of the Shapiro-Wilk statistic) or a two-sided Wilcoxon rank-sum test if they were not. Categorical data were analysed using contingency table analysis and the chi-squared or Fisher's test, as appropriate. The responses were scored by attributing one point to every correct answer and zero to every wrong answer. Possible range of score was from 0 (all wrong answers) to 14 (all right answers). Comparisons were performed between the three groups of physicians: primary care pediatricians, hospital pediatricians, and pediatric residents. All of the analyses were two-tailed, and $p$-values of 0.05 or less were considered significant. All questionnaires filled in by paediatricians and pediatric residents, regardless of their attitudes to vaccinate routinely in their practice, were included in the analyses.

All of the analyses were made using SAS version 9.1 software (SAS Institute, Cary, NC).

\section{Results}

Of the 750 physicians willing to participate (320 primary care pediatricians, 244 hospital pediatricians and 130 residents), 630 (84.0\%) returned completed questionnaires (407 females; mean age $43.5 \pm 11.2$ years). The response rate was similar in the three subgroups: $83.7 \%$ among primary care pediatricians, $81.3 \%$ among hospital pediatricians, and $82.5 \%$ among residents.

Table 1 shows the general characteristics of the respondents, $42.5 \%$ of whom were primary care pediatricians, $38.8 \%$ hospital pediatricians, and $18.7 \%$ pediatric residents. According to the national current practice, only a minority of the physicians usually administered vaccinations and used allergy tests in their routine practice, but these habits were significantly less common among the pediatric residents $(p<0.05)$.

Table 1

General characteristics of the surveyed physicians.

\begin{tabular}{|c|c|c|c|}
\hline Characteristics & $\begin{array}{l}\text { Primary care } \\
\text { pediatricians } \\
(n=268)\end{array}$ & $\begin{array}{l}\text { Hospital } \\
\text { pediatricians } \\
(n=244)\end{array}$ & $\begin{array}{l}\text { Pediatric } \\
\text { residents } \\
(n=118)\end{array}$ \\
\hline \multicolumn{4}{|l|}{ Gender, No. (\%) } \\
\hline Females & $176(65.7)$ & $149(61.1)$ & $82(69.5)$ \\
\hline Males & $92(34.3)$ & $95(38.9)$ & $36(30.5)$ \\
\hline \multicolumn{4}{|l|}{ Age, years } \\
\hline Mean \pm SD & $50.6 \pm 9.63$ & $44.5 \pm 9.74$ & $28.7 \pm 4.36^{*}$ \\
\hline $\begin{array}{l}\text { Vaccinations administered } \\
\text { routinely, No. (\%) }\end{array}$ & $88(32.8)$ & $69(28.3)$ & $10(8.5)^{*}$ \\
\hline $\begin{array}{l}\text { Allergy test used routinely, } \\
\text { No. (\%) }\end{array}$ & $85(31.7)$ & $60(24.6)$ & $16(13.5)^{*}$ \\
\hline
\end{tabular}

SD, standard deviation. * $p<0.05$ vs primary care and hospital pediatricians; there were no other significant between-group differences. 
Table 2

Knowledge of how to vaccinate children with egg allergy.

\begin{tabular}{|c|c|c|c|}
\hline Question & $\begin{array}{l}\text { Primary care pediatricians } \\
(n=268)\end{array}$ & $\begin{array}{l}\text { Hospital pediatricians } \\
(n=244)\end{array}$ & $\begin{array}{l}\text { Pediatric residents } \\
(n=118)\end{array}$ \\
\hline \multicolumn{4}{|l|}{ Which of these sentences is correct? } \\
\hline $\begin{array}{l}\text { MMR vaccine should only be administered to children who have } \\
\text { already started eating eggs without adverse events }\end{array}$ & $33(12.3)$ & $24(9.8)$ & $16(13.5)$ \\
\hline $\begin{array}{l}\text { In the case of moderate or severe egg allergy, MMR vaccine cannot be } \\
\text { administered }\end{array}$ & $12(4.4)$ & $10(4.0)$ & $7(5.9)$ \\
\hline $\begin{array}{l}\text { In the case of egg allergy of any type, MMR vaccine should be } \\
\text { administered in hospital under controlled conditions }\end{array}$ & $35(13.1)$ & $42(17.2)$ & $33(27.9)^{*}$ \\
\hline$\frac{\text { MMR vaccine can be administered to children with any type of egg }}{\text { allergy without taking specific precautions }}$ & $182(67.9)$ & $161(65.9)$ & $46(38.9)^{*}$ \\
\hline I do not know & $6(2.2)$ & $7(2.9)$ & $16(13.5)^{*}$ \\
\hline \multicolumn{4}{|l|}{ Which of these sentences is correct? } \\
\hline In the case of egg allergy, influenza vaccination is not recommended & $18(6.7)$ & $15(6.1)$ & $8(6.8)$ \\
\hline In the case of egg allergy of any type, influenza vaccination can be given & $15(5.6)$ & $17(6.9)$ & $7(5.9)$ \\
\hline \multicolumn{4}{|l|}{ without precaution using injectable vaccines with a low egg protein content } \\
\hline $\begin{array}{l}\text { In the case of moderate to severe egg allergy, the advantages and } \\
\text { benefits of influenza vaccination should be evaluated carefully }\end{array}$ & $184(68.7)$ & $165(67.6)$ & $73(61.8)$ \\
\hline $\begin{array}{l}\text { Influenza vaccination is dangerous in patients with egg allergy, } \\
\text { regardless of the severity of the allergy }\end{array}$ & $14(5.2)$ & $14(5.7)$ & $9(7.6)$ \\
\hline I do not know & $37(13.8)$ & $33(13.5)$ & $21(17.8)$ \\
\hline \multicolumn{4}{|l|}{ How do you vaccinate a child with mild to moderate egg allergy? } \\
\hline $\begin{array}{l}\text { I recommend vaccination in hospital and not in normal vaccination } \\
\text { centres }\end{array}$ & $46(17.2)$ & $39(15.9)$ & $25(21.2)$ \\
\hline I postpone MMR and influenza vaccines & $11(4.1)$ & $9(7.6)$ & $1(0.8)^{*}$ \\
\hline I administer MMR vaccine but not influenza vaccination & $27(10.1)$ & $25(10.2)$ & $11(9.3)$ \\
\hline I administer MMR and influenza vaccines with no precautions & $133(49.6)$ & $124(50.8)$ & $28(23.7)^{*}$ \\
\hline $\begin{array}{l}\text { I ask for an egg protein skin test or egg challenge test and on the basis } \\
\text { of the results I decide what to do }\end{array}$ & $30(11.1)$ & $25(10.2)$ & $9(7.6)$ \\
\hline I do not know & $21(7.8)$ & $22(9.0)$ & $44(37.3)^{*}$ \\
\hline
\end{tabular}

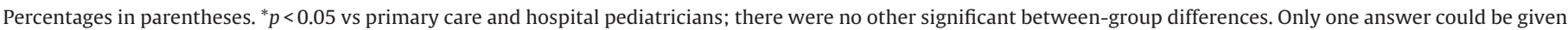
to each question. The correct answers have been underlined.

Table 2 summarises the data concerning the respondents' knowledge of vaccination-related problems in children with egg allergy. The correct answer that MMR vaccine can be administered to children with egg allergy of any type without the need for any specific precautions was given by about $65-68 \%$ of primary care and hospital pediatricians, but fewer than $40 \%$ of residents $(p<0.05)$. Moreover, a very small number of physicians (less than $10 \%$ without any between-group differences) correctly indicated that influenza vaccine with a very low egg protein content can be administered without the need for special precautions in the presence of egg allergy of any type. Finally, about $50 \%$ of the hospital and primary care pediatricians correctly answered that MMR and influenza vaccines can be administered to children with mild-moderate egg allergy without the need for precautions, but by only about $26 \%$ of the residents $(p<0.05)$. Among residents, about $37 \%$ did not know the correct answer to this last question.

Table 3 shows the data concerning the answers to questions regarding the vaccination of children with atopic dermatitis or urticaria. More than $70 \%$ of the pediatricians in the two groups and about $65 \%$ of residents $(p<0.05)$ correctly said that atopic dermatitis is not a contraindication for vaccine administration, and respectively, $50 \%$ and $25 \%(p<0.05)$ correctly said that children with atopic dermatitis can receive all of the same vaccines as healthy children. Among residents, about $41 \%$ did not know how to vaccinate a child with atopic dermatitis. Correctly, a history of urticaria was not considered a problem for vaccine administration by about $45 \%$ of the pediatricians and $35 \%$ of the residents $(p<0.05)$. Only a minority of the pediatricians and residents correctly said that no specific precaution is required in the case of vaccinations administered to children experiencing urticaria without anaphylactic shock after a previous vaccination. In this case, about $26 \%$ of residents did not know how to vaccinate the child.

Table 4 shows the responses of the participants to questions concerning how to vaccinate subjects with a suspected or known allergy to drugs and those receiving steroids. About $70 \%$ of the pediatricians and $55 \%$ of the residents $(p<0.05)$ correctly said that there is no specific precaution for vaccination in case of a history of drug allergy without anaphylactic shock, but only a minority correctly said that no specific precaution is recommended for children whose first-degree relatives have a history of anaphylactic shock, and many declared that they did not know how to manage this situation. The answers were similar results in the case of a family history of anaphylactic shock among relatives not of the first-degree, with the residents showing less knowledge than the two groups of pediatricians ( $p<0.05$ ). Finally, about $60-65 \%$ of the pediatricians and $45 \%$ of the residents $(p<0.05)$ correctly answered that vaccinations need to be postponed in children receiving steroid therapy or prophylaxis only in the case of the administration of a prednisone-equivalent dose of $>2 \mathrm{mg} / \mathrm{kg} /$ day.

Table 5 shows the answers to questions about how to vaccinate children with respiratory allergies. Correctly, allergic rhinitis was not considered a problem by about $80 \%$ of the pediatricians and $55 \%$ of the residents $(p<0.05)$, and influenza and pneumococcal vaccines were identified as being recommendable by, respectively, 70\% and $60 \%(p<0.05)$. Finally, most of the pediatricians and a minority of the residents $(p<0.05)$ said that specific precautions need to be adopted only in the case of severe asthma. About $26 \%$ of residents did not know how to manage vaccinations in asthmatic children.

Table 6 shows the mean scores \pm SD associated with an adequate knowledge of the use of vaccinations in allergic patients. The mean score of the primary care pediatricians $(9.22 \pm 3.39)$ was similar to that of the hospital pediatricians $(9.14 \pm 2.66)$, and both were significantly better than those of the residents $(7.31 \pm 3.45 ; p<0.05)$. The factors associated with better results were an age $\geq 45$ years, and the routine administration of vaccinations and routine use of allergy tests in clinical practice.

No difference by geographical area was observed in the frequency of correct answers given to the different sections as well as in the mean score obtained in the whole questionnaire. 
Table 3

Knowledge of how to vaccinate children with atopic dermatitis or urticaria.

\begin{tabular}{|c|c|c|c|}
\hline Question & $\begin{array}{l}\text { Primary care pediatricians } \\
(n=268)\end{array}$ & $\begin{array}{l}\text { Hospital pediatricians } \\
(n=244)\end{array}$ & $\begin{array}{l}\text { Pediatric residents } \\
(n=118)\end{array}$ \\
\hline \multicolumn{4}{|l|}{ What limitations are recommended for children with atopic dermatitis? } \\
\hline None & $201(75.0)$ & $188(77.0)$ & $77(65.3)^{*}$ \\
\hline \multicolumn{4}{|l|}{ They can be vaccinated only in the absence of active lesions } \\
\hline They can be vaccinated only if they are not using topical steroids & $12(4.5)$ & $14(5.7)$ & $7(5.9)$ \\
\hline \multirow[t]{2}{*}{ In the case of serious disease, they should be vaccinated in hospital } & $21(7.8)$ & $15(6.1)$ & $7(5.9)$ \\
\hline & $27(10.1)$ & $22(9.0)$ & $15(12.7)$ \\
\hline I do not know & $7(2.6)$ & $5(2.0)$ & $12(10.2)$ \\
\hline \multicolumn{4}{|l|}{ How do you vaccinate a child with atopic dermatitis? } \\
\hline In case of serious disease, I ask for a consultation & $24(8.9)$ & $19(7.8)$ & $8(6.8)$ \\
\hline I wait until the skin lesions are no longer active & $48(17.9)$ & $36(14.8)$ & $12(10.2)$ \\
\hline I recommend vaccinations as in healthy children & $143(53.4)$ & $125(51.2)$ & $30(25.4)^{*}$ \\
\hline I perform a skin test with vaccines before vaccination & $5(1.9)$ & $5(2.0)$ & $1(0.8)$ \\
\hline $\begin{array}{l}\text { If the child also has a history of wheezing, I vaccinate him/her in } \\
\text { hospital and not in normal vaccination centers }\end{array}$ & $27(10.1)$ & $31(12.7)$ & $18(15.3)$ \\
\hline I do not know & $21(7.8)$ & $28(11.5)$ & $49(41.5)^{*}$ \\
\hline \multicolumn{4}{|l|}{ What precautions are recommended in children with a history of urticaria? } \\
\hline $\begin{array}{l}\text { Vaccinations should always be administered in a hospital and not in } \\
\text { normal vaccination centres }\end{array}$ & $104(38.8)$ & $96(39.3)$ & $46(38.9)$ \\
\hline No specific precaution is recommended & $119(44.4)$ & $106(43.4)$ & $41(34.7)^{*}$ \\
\hline$\overline{\text { Precautions are required for live attenuated viral vaccines }}$ & $12(4.5)$ & $10(4.1)$ & $4(3.4)$ \\
\hline An antihistamine drug is recommended before vaccination & $12(4.5)$ & $12(4.9)$ & $8(6.8)$ \\
\hline I do not know & $21(7.8)$ & $20(8.2)$ & $19(16.1)^{*}$ \\
\hline \multicolumn{4}{|c|}{ In the case of urticaria without anaphylactic shock after a vaccination, how should the child's vaccination schedule be continued? } \\
\hline $\begin{array}{l}\text { He/she should always be vaccinated in hospital and not in normal } \\
\text { vaccination centres }\end{array}$ & $140(52.8)$ & $119(48.8)$ & $36(30.5)^{*}$ \\
\hline No specific precaution is recommended & $53(19.8)$ & $49(20.1)$ & $33(27.9)$ \\
\hline A skin test with the vaccines is recommended before administration & $5(1.9)$ & $5(2.0)$ & $0(0.0)$ \\
\hline Allergic blood examinations are recommended & $39(14.6)$ & $41(16.8)$ & $18(15.3)$ \\
\hline I do not know & $31(11.6)$ & $30(12.3)$ & $31(26.3)$ \\
\hline
\end{tabular}

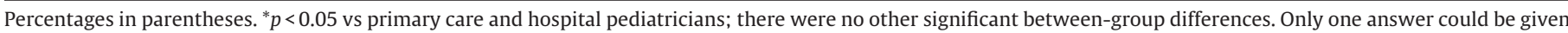
to each question. The correct answers have been underlined.

Table 4

Knowledge of how to vaccinate children with drug allergy.

\begin{tabular}{|c|c|c|c|}
\hline Question & $\begin{array}{l}\text { Primary care } \\
\text { pediatricians } \\
(n=268)\end{array}$ & $\begin{array}{l}\text { Hospital } \\
\text { pediatricians } \\
(n=244)\end{array}$ & $\begin{array}{l}\text { Pediatric } \\
\text { residents } \\
(n=118)\end{array}$ \\
\hline \multicolumn{4}{|c|}{ In the presence of a history of drug allergy without anaphylactic shock, which of the following is correct? } \\
\hline It is always better to vaccinate children in hospital & $46(17.2)$ & $40(16.4)$ & $24(20.3)$ \\
\hline Children have to be vaccinated in hospital & $16(5.9)$ & $12(4.9)$ & $7(5.9)$ \\
\hline It is recommended to perform skin test before vaccination & $4(1.5)$ & $4(1.6)$ & $16(13.5)^{*}$ \\
\hline No specific precaution is recommended & $187(69.7)$ & $178(72.9)$ & $64(54.2)^{*}$ \\
\hline$\overline{\text { I do not know }}$ & $15(5.6)$ & $10(3.7)$ & $7(5.9)$ \\
\hline \multicolumn{4}{|c|}{ In the presence of a family history of anaphylactic shock in first-degree relatives, how do you manage a child's vaccination? } \\
\hline I ask for a consultation & $20(7.5)$ & $18(7.4)$ & $7(5.9)$ \\
\hline I do not recommend any specific precaution & $83(30.9)$ & $77(31.5)$ & $19(16.1)^{*}$ \\
\hline I recommend a skin test with vaccines before each vaccination & $5(1.9)$ & $4(1.6)$ & $4(3.4)$ \\
\hline I recommend vaccination in hospital & $41(15.3)$ & $42(17.2)$ & $16(13.5)$ \\
\hline I do not know & $119(44.4)$ & $103(42.2)$ & $72(61.0)^{*}$ \\
\hline \multicolumn{4}{|c|}{ In the presence of a family history of anaphylactic shock in non first-degree relatives, how do you manage a child's vaccination? } \\
\hline I ask for a consultation & $11(4.1)$ & $9(3.7)$ & 2(1.7) \\
\hline I do not recommend any specific precaution & $142(52.9)$ & $128(52.5)$ & $37(31.4)^{*}$ \\
\hline 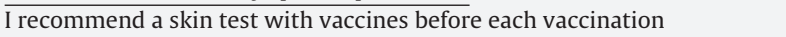 & $3(1.1)$ & $2(0.8)$ & $2(1.7)$ \\
\hline I recommend vaccination in hospital & $11(4.1)$ & $9(3.7)$ & $7(5.9)$ \\
\hline I do not know & $101(37.6)$ & $96(39.3)$ & $70(59.3)^{*}$ \\
\hline \multicolumn{4}{|l|}{ In the case of steroid therapy or prophylaxis, can vaccinations be administered? } \\
\hline It is always better to finish steroid administration & $40(14.9)$ & $35(14.3)$ & $18(15.3)$ \\
\hline $\begin{array}{l}\text { Even in the case of therapy with inhalatory drugs, it is better to } \\
\text { postpone vaccination }\end{array}$ & $16(5.9)$ & $12(4.9)$ & $8(6.7)$ \\
\hline $\begin{array}{l}\text { In case of therapy with oral steroids, it is always better not to vaccinate } \\
\text { regardless of steroid's dose }\end{array}$ & $35(13.1)$ & $31(11.6)$ & $14(11.9)$ \\
\hline \multicolumn{4}{|l|}{$\overline{\text { prednisone-equivalent dose of }>2 \mathrm{mg} / \mathrm{kg} / \mathrm{die}}$} \\
\hline I do not know & $9(3.3)$ & $7(2.9)$ & $26(22.0)^{*}$ \\
\hline
\end{tabular}

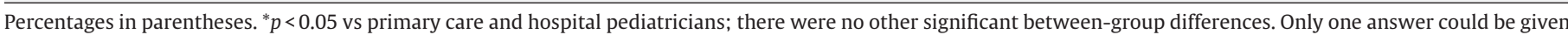
to each question. The correct answers have been underlined. 
Table 5

Knowledge of how to vaccinate children with respiratory allergy.

\begin{tabular}{|c|c|c|c|}
\hline Question & $\begin{array}{l}\text { Primary care } \\
\text { pediatricians } \\
(n=268)\end{array}$ & $\begin{array}{l}\text { Hospital } \\
\text { pediatricians } \\
(n=244)\end{array}$ & $\begin{array}{l}\text { Pediatric } \\
\text { residents } \\
(n=118)\end{array}$ \\
\hline \multicolumn{4}{|l|}{ Which of these sentences is correct in the case of children with allergic rhinitis? } \\
\hline $\begin{array}{l}\text { It is better to postpone vaccination if they are receiving prophylaxis with } \\
\text { inhalatory steroids or if they are undergoing desensitization }\end{array}$ & $18(6.7)$ & $15(6.1)$ & $24(20.3)^{*}$ \\
\hline $\begin{array}{l}\text { It is mandatory to vaccinate them in a season other than that in which their } \\
\text { allergy appears }\end{array}$ & $12(4.5)$ & $13(5.3)$ & $7(5.9)$ \\
\hline They can be vaccinated only in the case of mild or moderate allergic rhinitis & $12(4.5)$ & $12(4.9)$ & $6(5.1)$ \\
\hline$\frac{\text { They can be vaccinated regardless of prophylaxis with inhalatory steroids, }}{\text { desensitization, seasonality or the severity of allergic rhinitis }}$ & $214(79.9)$ & $195(79.9)$ & $66(55.9)^{*}$ \\
\hline I do not know & $12(4.5)$ & $10(4.1)$ & $18(15.2)^{*}$ \\
\hline \multicolumn{4}{|l|}{ What vaccinations are recommended for asthmatic children? } \\
\hline The same as for healthy children & $31(11.6)$ & $30(12.3)$ & $20(16.9)$ \\
\hline Influenza and pneumococcal vaccination & $196(73.1)$ & $170(69.7)$ & $74(62.7)$ \\
\hline$\overline{\text { Pneumococcal vaccination }}$ & $6(2.2)$ & $7(2.9)$ & $4(3.4)$ \\
\hline Influenza vaccination in children receiving chronic anti-asthma prophylaxis & $31(11.6)$ & $33(13.5)$ & $10(8.5)$ \\
\hline I do not know & $4(1.5)$ & $4(1.6)$ & $10(8.5)^{*}$ \\
\hline \multicolumn{4}{|l|}{ How do you manage vaccinations in asthmatic children? } \\
\hline $\begin{array}{l}\text { In the case of persistent asthma, I recommend vaccination in hospital and not } \\
\text { in normal asthmatic centres }\end{array}$ & $25(9.3)$ & $28(11.5)$ & $25(21.2)^{*}$ \\
\hline I do not recommend any specific precautions except in the case of severe asthma & $196(73.1)$ & $203(83.1)$ & $46(38.9)^{*}$ \\
\hline$\overline{\text { I recommend spirometry before each vaccination }}$ & $1(0.4)$ & $2(0.8)$ & $2(1.7)$ \\
\hline I recommend allergic examinations before each vaccination & $1(0.4)$ & $1(0.8)$ & $2(1.7)$ \\
\hline I evaluate carefully whether the vaccination is really useful & $22(8.2)$ & $23(9.4)$ & $12(10.2)$ \\
\hline I do not know & $12(4.4)$ & $12(4.9)$ & $31(26.3)^{*}$ \\
\hline
\end{tabular}

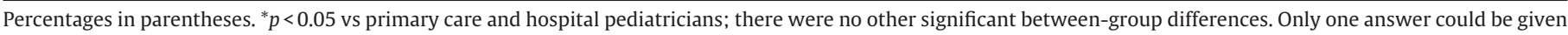
to each question. The correct answers have been underlined.

\section{Discussion}

To the best of our knowledge, this is the only recent study of the global knowledge of pediatricians to the use of vaccines in children with suspected or documented allergic problems. Although it was limited to Italian pediatricians, the data may also be of interest to experts living in other countries because they indicate the areas in which knowledge is likely to be poorer and therefore require educational planning. Though participation to the survey was voluntary, demographic characteristics of participating pediatricians and pediatric residents were similar to those of the Italian primary care pediatricians, hospital pediatricians and pediatric residents $[6,10]$.

The overall results indicate that pediatricians' knowledge of vaccination in allergic children is far from optimal, that there are no

\section{Table 6}

Scores showing the factors associated with an adequate knowledge of vaccinations for allergic patients.

\begin{tabular}{|c|c|c|c|}
\hline Variable & $\begin{array}{l}\text { Primary care } \\
\text { pediatricians } \\
(n=268)\end{array}$ & $\begin{array}{l}\text { Hospital } \\
\text { pediatricians } \\
(n=244)\end{array}$ & $\begin{array}{l}\text { Pediatric } \\
\text { residents } \\
(n=118)\end{array}$ \\
\hline \multicolumn{4}{|l|}{ Age } \\
\hline$<45$ years & $8.62(2.46)^{\wedge}$ & $8.44(2.33)^{-}$ & $7.22(3.43)^{*}$ \\
\hline$\geq 45$ years & $9.22(3.52)$ & $9.16(3.10)$ & n.a. \\
\hline \multicolumn{4}{|l|}{ Gender } \\
\hline Males & $9.25(3.19)$ & $9.19(2.79)$ & $7.44(3.58)^{*}$ \\
\hline Females & $9.19(3.46)$ & $9.09(2.63)$ & $7.19(3.31)^{*}$ \\
\hline \multicolumn{4}{|c|}{ Vaccinations administered routinely } \\
\hline Yes & $9.85(3.41)^{\circ}$ & $9.66(3.49)^{\circ}$ & $7.70(2.61)^{* \circ}$ \\
\hline No & $8.46(3.59)$ & $8.53(3.73)$ & $6.99(2.88)$ \\
\hline \multicolumn{4}{|c|}{ Allergy tests used routinely } \\
\hline Yes & $9.76(3.48)^{\#}$ & $9.49(3.22)^{\#}$ & $7.61(3.18)^{* \#}$ \\
\hline No & $8.52(3.55)$ & $8.49(3.16)$ & $6.88(2.97)$ \\
\hline
\end{tabular}

Mean values with standard deviations in parentheses. The score was calculated by giving 1 point for every right answer and zero to every wrong answer; the possible range of score was from 0 (all wrong answers) to 14 (all right answers). ${ }^{*} p<0.05$ vs primary care and hospital pediatricians; $p<0.05$ vs age $\geq 45$ years; ${ }^{\circ} p<0.05$ vs vaccinations not administered routinely; ${ }^{\#} p<0.05$ vs no allergy tests used routinely. There were no other significant between-group differences. differences between primary care and hospital pediatricians, and that pediatric residents know least.

Although there is no published studies on the time required by practicing physicians to adopt national and international guidelines, analysis of the different aspects of the relationship between vaccines and allergy make it possible to suggest that the high incidence of wrong answers to the questionnaire is at least partially due to the fact that the recent rapid and not always homogeneous changes in international health authority guidelines have caused some confusion. This seems to be true in the case of the administration of MMR and influenza vaccines to children with egg allergy. It is surprising that so many of the pediatricians and most of the residents think that a history of egg allergy contraindicates the administration of MMR vaccine, and that children with moderate or severe egg allergy should always to be referred to hospital to receive it under controlled conditions, because all of the currently available international guidelines clearly state that egg allergy does not affect its safety because it contains negligible amounts or no egg protein [19].

Misunderstandings among health professionals concerning the safety of MMR immunization in children with egg allergy have been previously reported [20] possibly because experts have reached total concordance only recently. Until a few years ago, there were significant differences in the approach to MMR: e.g., the guidelines published in 2000 by the British Society of Allergy and Clinical Immunology said that the only children who need to be vaccinated in hospital were those with an allergy to eggs in whom previous exposure had led to cardiorespiratory reactions and those with coexisting chronic active asthma requiring inhaled steroids or other prophylaxis [21], whereas their 2007 guidelines said that MMR vaccine can be routinely administered to all children with egg allergy but, as these guidelines were not adequately publicised, many primary care physicians remained unaware of them [20]. In the United States, the American Academy of Pediatrics (AAP) and the Advisory Committee on Immunization Practices (ACIP) stopped considering egg allergy a contraindication to MMR vaccination in 2003, and stated that its routine use did not require the use of special protocols or desensitization procedures [22]. The same is true of Italy, 
where the Ministry of Health has included egg allergy among the false contraindications to the administration of MMR vaccine since 2003 [23].

Another reason for pediatricians' mistakes is the fact that the companies producing and marketing MMR vaccines regularly state that people with a history of anaphylactic, anaphylactoid or other immediate reactions to egg ingestion should be vaccinated with extreme caution [24,25].

The data concerning influenza vaccine give rise to similar considerations. A substantial number of both hospital and primary care pediatricians, and most of the residents, proved to know little about its administration to children with egg allergy, and this can once again be at least partially attributed to differences in health authority guidelines causing doubts in pediatricians' minds. A number of recent studies have shown that influenza vaccines can be safely administered to children with egg allergy provided that a split-dose protocol is used, even if they have previously suffered an episode of anaphylaxis [26,27]. Moreover, there are case series showing that positive skin and intradermal tests do not predict reactivity [28].

However, the authorities in the United States do not include these findings in their recommendations and, in the case of children who have previously experienced severe anaphylaxis, recommend evaluating the real need for the vaccine or making use of systematic testing and a multidose protocol for positive patients [29]. The Italian authorities are even more restrictive because the national vaccination plan considers a previous severe anaphylactic reaction to any vaccine component (including egg) a contraindication [23]. Moreover, none of the guidelines prepared in the United States and Italy point out that the risk of adverse events related to egg allergy strictly depends on the amount of egg protein or that there is no risk of adverse events provided a vaccine with the lowest protein content is administered [30]. On the contrary, the amount of egg protein is considered in the UK, and the British Society of Allergy and Clinical Immunology suggests that children with egg allergy should receive a mammalian culture-based influenza vaccine [31].

There is no explanation other than a lack of knowledge for the data regarding vaccinations in children with atopic dermatitis, urticaria, or respiratory or drug allergies, or in those concomitantly receiving steroids. It has long been known that atopic dermatitis only contraindicates the use smallpox vaccine because of the increased risk of eczema vaccinatum [32]; all of the other vaccines can be safely administered to subjects with atopic dermatitis. Lesion-free atopic children with a history of urticaria can also be safely vaccinated because there are no data to support the hypothesis that infant vaccines can increase the risk of allergic disease [33].

The same is true in the case of drug allergies because it is well known that all vaccines can be given without any particular precautions unless it is suspected or has been proven that one of the components was responsible for a previous severe anaphylactic reaction in the child but not in his/her relatives [34].

It is also well known that steroid therapy does not contraindicate vaccination except when high doses are used: in such cases, it is better to postpone the vaccination if possible - not for safety reasons but in order to ensure adequate immunogenicity [35].

Finally, it is well known that patients with allergic rhinitis can receive any vaccine without increasing the risk of adverse events [36]. Furthermore, although there is no convincing evidence of its efficacy in reducing the risk of a new asthma attack [37], influenza vaccine is universally recommended in subjects with asthma $[22,29,30]$ and is not followed by any deleterious side effects, including the exacerbation of asthma episodes [38]. Only children with severe asthma at the time of vaccination and those who have previously suffered severe anaphylaxis need special precautions, such as a hospital referral.
The factors associated with an adequate knowledge of vaccination in allergic patients indicate that there is a need to increase post-graduate training and clinical practice in this field, as well as a need to increase the practice of routine vaccination and allergy testing among pediatricians. In Italy, as in our study population, only a minority of pediatricians routinely administer vaccine to children but they represent the main advisor for parents regarding vaccinations $[4,6]$. This means that the adequate knowledge of the pediatricians represents a major issue for giving a correct advice to parents and for reaching an optimal vaccination coverage. On the other hand, information and misinformation on vaccination in allergic children among parents may influence the pediatricians' behaviour and reduce the use of vaccines in these patients if the pediatricians are not adequately updated.

This study has some limitations. First of all, despite the pediatricians and pediatric residents registered at the Annual Congress of the Italian Society of Pediatrics and those who completed our questionnaire show general characteristics similar to that of the Italian pediatricians and pediatric residents $[6,10]$, it is possible that pediatricians who were more interested in this issue were more willing to participate in our survey. In this case, we would overestimated pediatricians' knowledge on this topic. Moreover, although we did not observe geographical differences, the survey was not designed for detecting such a difference and a larger sample size could be useful for this type of comparison. Furthermore, although we showed that physicians who administered vaccinations routinely had significantly higher scores of those who did not administer them, only a minority of pediatricians routinely administer vaccinations in their practice in Italy and a larger sample size is required to analyze precisely the differences in knowledge among physicians who administered routinely vaccines and those who did not administer them. However, global evaluation of the data collected in this study suggests that knowledge regarding the use of vaccines in children with allergic problems is inadequate in Italy and, in most cases, may lead to parents being given the wrong information and a consequent reduction in vaccination rates. As childhood vaccination remains an essential part of childhood health and should not be withheld even from children with previously diagnosed allergies, it is essential to plan educational programmes capable of resolving any doubts and offer all children the greatest possible protection against preventable diseases. As the poorest knowledge was found among residents, particular attention should be paid to them. Finally, evidence-based guidelines for allergic should be drawn up that take into account the specific nature of the individual allergies and each vaccine's particular characteristics.

\section{Acknowledgements}

We would like to thank Nicola Principi for his support in organising the study and preparing the manuscript, and all of the pediatricians and pediatric residents who participated in the study. This study was supported by a grant from the Italian Ministry of Universities, Project No. 2005068289_001.

\section{References}

[1] Andre FE, Booy R, Bock HL, Clemens J, Datta SK, John TL, et al. Vaccination greatly reduces disease, disability, death and iniquity worldwide. Bull World Health Organ 2008;86:140-6.

[2] Tickner S, Leman PJ, Woodcock A. Parents' views about pre-school immunization: an interview study in southern England. Child Care Health Dev 2010;36:190-7.

[3] Benin AL, Wisler-sher W, Colson E, Shapiro ED, Holmboe ES. Qualitative analysis of mothers' decision making about vaccines for infants: the importance of trust. Pediatrics 2006;117:1532-41.

[4] Esposito S, Marchisio P, Droghetti R, Lambertini L, Faelli N, Bosis S, et al. Influenza vaccination coverage among children with high-risk medical conditions. Vaccine 2006;24:5251-5. 
[5] Flanagan-Klygis EA, Sharp L, Frader JE. Dismissing the family who refuse vaccines: a study of pediatricians' attitudes. Arch Pediatr Adolesc Med 2005; 159:929-34.

[6] Anastasi D, Di Giuseppe G, Marinelli P, Angelillo IF. Paediatricians knowledge, attitudes, and practices regarding immunizations for infants in Italy. BMC Public Health 2009;9:463.

[7] Cohen NJ, Lauderdale DS, Shete PB, Seal JB, Daum RS. Physician knowledge of catch-up regimens and contraindications for childhood immunizations. Pediatrics 2003;111:925-32.

[8] Schaffer SJ, Szilagyi PG, Shone LP, Ambrose SJ, Dinn MK, Barth RD, et al. Physician perspective regarding pneumococcal conjugate vaccine. Pediatrics 2002; $110: \mathrm{e} 68$.

[9] Zimmerman RK, Mieczkowski TA, Mainzer HM, Medsger AR, Nowalk MP. Understanding physician agreement with varicella immunization guidelines. Prev Med 2002;35:135-42.

[10] Esposito S, Bosis S, Pelucchi C, Begliatti E, Rognoni A, Bellasio M, et al. Pediatrician knowledge and attitudes regarding human papillomavirus disease and its prevention. Vaccine 2007;25:6437-46.

[11] Sabnis S, Pomeranz AJ, Mao J. Physician beliefs and practices regarding the use of hepatitis A vaccine. WMJ 2007;106:211-4.

[12] Zent O, Arras-Reiter C, Broeker M, Hennig R. Immediate allergic reactions after vaccinations - a post-marketing surveillance review. Eur J Pediatr 2002;161:21-5.

[13] Bohike K, Davis RL, Marcy SM, Braun MM, DeStefano F, Black SB, et al. Risk of anaphylaxis after vaccination of children and adolescents. Pediatrics 2003;112:815-20.

[14] Rüggeberg JU, Gold MS, Bayas JM, Blum MD, Bonhoeffer J, Friedlander S, et al. Anaphylaxis: case definition and guidelines for data collection, analysis, and presentation of immunization safety data. Vaccine 2007;25:5675-84.

[15] Bonhoeffer J, Heininger U. Adverse events following immunization: perception and evidence. Curr Opin Infect Dis 2007;20:237-46.

[16] Erlewyn-Lajeunesse M, Bonhoeffer J, Rüggeberg JU, Heath PT. Anaphylaxis as an adverse event following immunization. J Clin Pathol 2007;60:737-9.

[17] Rottem M, Shoenfeld Y. Vaccination and allergy. Curr Opin Otolaryngol 2004; 12:223-31.

[18] Mitka M. Safe vaccination usually possible in persons with suspected vaccine allergies. JAMA 2009;302:2193.

[19] Kelso JK. Update on vaccination for allergic children. Expert Rev Vaccines 2009;8:1541-6.

[20] Ainsworth E, Debenham P, Carrol ED, Riordan FAI. Referrals for MMR immunization in hospital. Arch Dis Child; 2010 [Epub April 6].

[21] Khakoo GA, Lack G. Recommendations for using MMR vaccine in children allergic to egg. BMJ 2000;320:929-32.
[22] American Academy of Pediatrics. Committee on Infectious Diseases. Red book. Section 1. Active and passive immunization. 26th ed.; 2003. p. 46.

[23] Italian Ministry of Health. Piano Nazionale Vaccini 2005-2007. Available at: http://www.salute.gov.it.

[24] Sanofi Pasteur MSD. Summary of product characteristics M-M-RVAXPro; 2008. Available at: http://emc.medicines.org.uk/medicine/20968/SPC/MMRVAXPRO.

[25] GlaxoSmithKline. Summary of product characteristics Priorix GlaxoSmithKline Vaccines 2008. Available at: http://emc.medicines.org.uk/ document.aspx?documentld=2054.

[26] Murphy KR, Strunk RC. Safe administration of influenza vaccine in asthmatic children hypersensitive to egg protein. J Pediatr 1985;106:931-3.

[27] James JM, Zeiger RS, Laster MR, Fasano MB, Gern JE, Mansfield LE, et al. Safe administration of influenza vaccine to patients with egg allergy. J Pediatr 1998;133:624-8.

[28] Anolik R, Spiegel W, Posner M, Jakabovics E. Influenza vaccine testing in egg sensitive patients. Ann Allergy 1992;68:69.

[29] Fiore AE, Shay DK, Broder K, Iskander JK, Uyeki TM, Mootrey G, et al. Centers for Disease Control and Prevention. Prevention and control of seasonal influenza with vaccines: recommendations of the Advisory Committee on Immunization Practices (ACIP), 2009. MMWR Recomm Rep 2009;58(RR-8):1-52 [Erratum in: MMWR Recomm Rep 2009;58:896-7].

[30] Esposito S, Gasparini C, Martelli A, Zenga A, Tremolati E, Varin E, et al. Safe administration of an activated virosomal adjuvanted influenza vaccine in asthmatic children with egg allergy. Vaccine 2008;26:4664-8.

[31] Nasser S, Brathwaite N. Swine flu vaccination in patients with egg allergy. Clin Exp Allergy 2009;39:1288-90.

[32] Rottem M, Shoenfeld Y. Vaccination allergy. Curr Opin Otolaryngol 2004; $12: 223-31$.

[33] Koppen S, de Groot R, Neijens HJ, Nagelkerke N, van Eden W, Rumke HC. No epidemiological evidence for infant vaccinations to cause allergic disease. Vaccine 2004;22:3375-85.

[34] Kelso JM. Update on vaccination guidelines for allergic children. Expert Rev Vaccines 2009;8:1541-6.

[35] Esposito S, Cecinati V, Brescia L, Principi N. Vaccinations in children with cancer. Vaccine 2010;28:3278-84.

[36] Stanaland BE. Therapeutic measures for prevention of allergic rhinitis/asthma development. Allergy Asthma Proc 2004;25:11-5.

[37] Anderson M, Carroll W. Virus vaccines and children with asthma. Curr Opin Allergy Clin Immunol 2009;9:44-9.

[38] Kramarz P, Destefano F, Gargiullo PM, Chen RT, Lieu TA, Davis RL, et al. Does Influenza vaccination prevent asthma exacerbation in children? J Pediatr 2000;138:306-10. 